(038-039) Two proposals to deal with reprints and translations of publications first printed before the relevant nomenclatural starting-point date, and with recent posthumous publications of pre-Linnaean authors

Sennikov, Alexander N.

2015-05

Sennikov , A N 2015 , ' (038-039) Two proposals to deal with reprints and translations of publications first printed before the relevant nomenclatural starting-point date, and with recent posthumous publications of pre-Linnaean authors ', Taxon, vol. 64 , no. 2 , pp. 392-393 . https://doi.org/10.12705/642.13

http://hdl.handle.net/10138/155204

https://doi.org/10.12705/642.13

acceptedVersion

Downloaded from Helda, University of Helsinki institutional repository.

This is an electronic reprint of the original article.

This reprint may differ from the original in pagination and typographic detail.

Please cite the original version. 
PROPOSALS TO AMEND THE CODE

Edited by Nicholas J. Turland \& John H. Wiersema

\title{
(038-039) Two proposals to deal with reprints and translations of publications first printed before the relevant nomenclatural starting-point date, and with recent posthumous publications of pre-Linnaean authors
}

\author{
Alexander N. Sennikov \\ Botanical Museum, Finnish Museum of Natural History, University of Helsinki, Unioninkatu 44, P.O. Box 7, 00014 Helsinki, Finland; \\ and Herbarium, Komarov Botanical Institute of Russian Academy of Sciences, Prof. Popov str. 2, 197376 St. Petersburg, Russia; \\ alexander.sennikov@helsinki.fi
}

DOI http://dx.doi.org/10.12705/642.13

Recent discussions about the nomenclatural impact of the German translation of a work by Vaillant, posthumously published after the nomenclatural starting-point date for valid publication of Spermatophyta (see Greuter \& al. in Taxon 54: 149-174. 2005; Brummitt in Taxon 57: 663. 2008; Greuter in Taxon 57: 1015-1016. 2008), had clearly shown that the problem is greater than protection of a few currently accepted names against those featured in the translation.

First of all, this concerns consistency of treatment of old publications. Among the works of "pre-Linnaean" character but published after 1753, which are listed among opera utique oppressa, there is already a work of Feuillée (Journal des observations ...) that is a post-Linnaean translation of the pre-Linnaean publication. Developing a common policy instead of dealing with singular cases one by one when they come to light is, I believe, more consistent and productive.

Then, there is the second part of the problem which has been completely overlooked. Since different editions of the same book, with or without alterations, are treated as effectively published (simply because there is no such restriction in the rules), this means that any subsequent reproduction of a historical book is effectively published. By now we have a number of "classical" reprints ranging from Sprengel's edition of Dioscoridis (1829), through the Ray Society classics of the mid-20th century, to the magnificient quarto-sized Dover's Gerard (1975) and Stanford's Fuchs (1999), and, after all, cheap contemporary facsimiles of scanned historical books with mostly electronic circulation. Note that the very recent flow of routine facsimile editions is accompanied with paper versions printed on demand, and also with International Standard Book Numbers assigned, thus satisfying all provisions of effective publication. Several of these books were originally published before the first edition of the Species plantarum, and potentially they may be searched for plant names, at least at the level of genus, which have not been accepted in other post-1753 publications.

My original proposal to exclude reprinted and translated pre-1753 books from the nomenclature (Sennikov in Taxon 59: 307-308. 2010) was not accepted in Melbourne; one reason for rejection was probably because the extent of the problem had been underestimated. Hereby I propose this change to the rules again, in a belief that cutting this Gordian knot with a single strike is an efficient action that is free of possible side effects.
(038) Proposal to discard the nomenclatural value of reprints and translations of publications first printed before the relevant nomenclatural starting-point date by adding a new Art. 13.5 with a new Note and a new Example:

"13.5. For nomenclatural purposes, all reprints and translations, published after the relevant nomenclatural starting-point date, of original works first published before that date are regarded as having been published only on the original date, with none of the names included therein being validly published."

"Note 2. Exempt from the provisions of Art. 13.5 is one part of Linnaeus's Amoenitates academicae (vol. 3, 1756)."

"Ex. 4bis. "Helminthotheca" was not validly published in Steinwehr's translation of Vaillant's work (in Königl. Akad. Wiss. Paris Anat. Abh. 5: 731. 1754) that was originally published before 1753 (Vaillant in Hist. Acad. Roy. Sci. Mém. Math. Phys. (Amsterdam, $8^{\circ}$ ) 1721: 267. 1725). The generic name Helminthotheca is to be correctly attributed to Zinn (1757), who was the first to fulfill conditions of its valid publication after the starting-point date."

The only exception from this new rule is allowed for the Linnaean Amoenitates academicae that is an authorized reprint which was published with due corrections and additions when the text was viewed as outdated by the author. Other exceptions may be added if and when found desirable.

A few generic names are currently treated as validly published from the pirated reprint of early Linnaean works, Opera varia (1758). Such names were not accepted by Linnaeus in 1758, and ascribing their valid publication to him may be correct under the formal rules but is historically illogical. Besides, one may doubt that the "Linnaean" Opera varia may be considered as a place of valid publication at all. According to Art. 36.1, in order to be validly published names are to be "accepted by the author in the original publication". Linnaeus definitely accepted the relevant names in the original publications which had been published before 1753, but he cancelled those names by revising their nomenclature in his subsequent works.

Fortunately, removing Opera varia from the market of botanical nomenclature will have very little practical impact, just changing the dates of valid publication of a few generic names.

Should this proposal be accepted, six entries in Appendix III, which were changed in the Vienna Code (McNeill \& al. in Regnum 
Veg. 146. 2006) so as to cite the place of valid publication by Vaillant, would be returned to their state in the Saint Louis Code (Greuter $\&$ al. in Regnum Veg. 138. 2000). Six additional entries in the list of conserved and rejected names in Appendix III would also need correcting, mostly returning to the stage of the unofficial Brittonia Rules (Camp \& al. in Brittonia 6: 1-120. 1947). These changes and corrections, which do not affect priority of accepted names, are listed elsewhere (Sennikov, 1.c.).

(039) Proposal to eliminate the nomenclatural impact of recent posthumous publications of pre-Linnaean authors by adding a new Art. 30.9:

"30.9. First publication on or after 1 January 1900 of works written before 1 May 1753 does not constitute effective publication."

This provison is to outlaw a possible effect of the first publication of pre-Linnaean works, survived in unpublished manuscripts, in recent times when paper and subsequently electronic publication of books became reasonably easy and affordable. Such publications, although of undoubtful historical value, may pose problems to nomenclature should someone treat them formally and seriously as a source of valid publication (e.g., of generic names). However fantastic this possibility may appear, I would like to exclude this problem in general and in advance, to prevent lovers of botanical antiquities from digging the dust.

The starting date of this new provision is established arbitrarily to include the complete 20th century into the period of "recent times" by which plant taxonomists had nearly stopped to look for nomenclatural novelties in works that were not using binomial nomenclature. This date may be changed if deemed necessary.

\section{Acknowledgements}

The first proposal results from discussions in the Nomenclature Committee for Vascular Plants. Nicholas Turland (Berlin) is thanked for refined wording of the proposals. 